\title{
Novel Method of Integrated Solar Panel Cleaner
}

\author{
L. Chitra, Ranjith R, Praveen A, Pragatheeswaran, Divya Raj
}

\begin{abstract}
Solar energy is most sought-after energy resources nowadays. But they face a major crisis of reduced panel life times and performance issues. In order to overcome these issues, we have proposed an integrated panel cleaner using electrostatic and vacuum suction method. The panel cleaner is programmed to remove the accumulated dust by non-contact method and without using water. The controls are given using Arduino controller which is pre-programmed to clean autonomously from the input obtained from the sensors. Dust accumulation in the photovoltaic panel reduces its spread, resulting in reduced power output and loss of power generation. Moreover, in India bird droppings are also a big threat to panels while cleaning. This can be removed with the help of vacuum suction tube which operates on low pressure negative suction. Water when used for cleaning develops strains which contain sediment chemical salts. Moreover, water should also be cleaned before utilisation by cleaners which incur additional costs for performing cleaning operations. The sole purpose of this project is to develop an automated panel cleaning technology wherein cleaning process takes place without much power and water consumption.
\end{abstract}

Keywords: Inrush current, quasi ZSI, two switched network, ripple current, sliding mode controller.

\section{INTRODUCTION}

$\mathrm{T}_{\mathrm{h}}$ he global increase in the human population and the need for energy has favored the rise of solar energy [1-2]. It is the most renewable energy source currently available.[3] It has been decided that 84 minutes of solar radiation falling on Earth can produce enough energy for the entire world in a year, but the main problem here is the capture of solar power. Solar energy is very expensive compared to other types of energy, which is due to the high solar panel cost and its maintenance. According to Abd-Elhady, [4-5] There are five factors that mainly affect the performance of PV panels, such as surface temperature, absorption of solar radiation, solar monitoring, design configuration and cleanliness of the panel surface. Here we intend to improve the fifth factor that is panel efficiency by proper design configuration and maintain the cleanliness of the solar panel with improved cleaning concepts. We have conceptualized here an integrated cleaning strategy with electrostatic and vaccum technology.

Revised Manuscript Received on December 11, 2019

Dr. L.Chitra*, Associate Professor, Department of Electrical and Electronics Engineering, Aarupadai Veedu Institute of Technology, Chennai, Tamil Nadu, India.

Ranjith. R, UG Student, Department of Electrical and Electronics India

Praveen .A, Pragatheeswaran, Divya Raj, UG Student, Department of Electrical and Electronics Engineering, Aarupadai Veedu Institute of Technology, Chennai, Tamil Nadu, India. Engineering, Aarupadai Veedu Institute of Technology, Chennai, Tamil Nadu,

[6] There are 4 main methods that are used to clean solar panels nowadays; they are manual, automatic, natural and passive methods which are used. Though there are several cleaning strategies available here we propose a improved non-contact and dry cleaning technique. This proposal is a concept of integrating and combining two cleaning strategies together one for smaller particles of dust (electrostatic negative ion generator) and other for larger dust deposition (vaccum cleaning technology).

The Reduction in solar panel efficiency has been a major problem for many years this can be eradicated by effective panel cleaning techniques. [7] Although manual labour cleaning and cleaning using water are the most prominent methods of cleaning, this can be disastrous at times. For instance, when we employ manual labour it may lead to panel damage. Or when we use water for cleaning, sedimentation may occur depending upon the water used for cleaning. This leads to pre-cleaning of water used and ads up to additional cost for purifying the water before using for cleaning. Automatic cleaning strategy employed beforehand also uses water for cleaning and piping cost increases the cost of panel cleaner more and more [8-9].

Electrostatic force is generated by negative ion generator which passes and transfers negative charges to the dust particles which gets attracted to the positively charged conducting plate. [10] Dust is removed from the PV panel when the electrically charged wave breaks on the surface of the PV panel. [11-14] this technique provides easy and efficient means of dust removal without damaging the solar panel. Generally, the panel cleaner is programmed to operate only in day time as this saves unnecessary cleaning during night. Light sensing element is used here to check the condition, so as to maximize the power generating potential during daily service.

Another method conceptualized here is vacuum suction which creates negative pressure and the difference in the pressure between atmosphere and vacuum tube generated results in suction of dust particles. The main idea behind implementing vacuum tube is to remove wet and sticky dust deposited on the panel. The sensing element senses the dust present on the board and when this intensity arises above a pre-set value and then the vacuum suction tube starts functioning.

Next the important sensing element used here is load cell. The load cell senses the difference in the weight in the pv module which generates the weight difference to the controller. The controller works according to the commands after receiving the signal from the sensing element. 
Next the intensity of the dust is monitored by IR sensor which sends impulse signals to the controller module and which in turn activates the suction pump which cleans the dirt or bird poops deposited on the PV module. The load cell input is again verified and the end of the panel is detected by the ultrasonic sensing element placed on both sides of the cleaning module.

It is also a self-sufficient panel cleaner that means the power required to run the panel cleaner is generated by a small solar panel mounted on the cleaning module. The supply panel provides the necessary power required to operate the cleaning system. The power obtained from the supply panel is stored on the battery storage attached with the cleaning module. Thus, it also minimizes the cost involved for power supply of cleaning module. The Arduino controller is used as it is highly reliable and performs accurate calculation and gives necessary command to the cleaning unit.

This cleaner unlike others rectifies the difficulty issues faced by other solar panel cleaners. It does incur any sediment deposit and panel damage unlike others. The main advantage of this panel is that it highly improves the panel efficiency, lifetime and makes the panel to provide a consistent \& stabilized output.

\section{REVIEW OF OTHER CLEANING STRATEGIES}

Some of the cleaning strategies employed at present are reviewed below to get a clear picture of advantages and disadvantages with their working. The cleaning strategies include:

- Manual cleaning

- Automatic cleaning

- Natural cleaning

- Passive surface cleaning

\section{A. Manual Cleaning Methodologies}

Manual cleaning techniques include a wide range of categories such as

- Water and soft cloth wiping

- Detergent/water rinsing

- Surfactance

- Water jet or surface brushing

Most manual cleaning strategy includes water as a cleaning tool for cleaning. Spraying water on the photovoltaic cells increases the photovoltaic efficiency of the system. This reduces the panel temperature and increases the lifetime of the panel. Whereas the drawback with this is labour errors and sedimentation of dust particles after cleaning using water. The dust deposition effect on the solar photovoltaic module was found to be smaller. But the performance was much affected due to local problem of bird droppings which would result in dropping inefficiency of the panel output. Fig. 1.shows the power reduction due to dust accumulation on solar panel Surface brushing may sometimes affect and damage the solar panels during cleaning process. The anionic and cationic surfactants are one of the methods used for dust removal from the solar panels. For the deposited sand particles anionic is most effective surfactant while compared to cationic surfactants. But they too face drawbacks in terms of cost and effective handling.
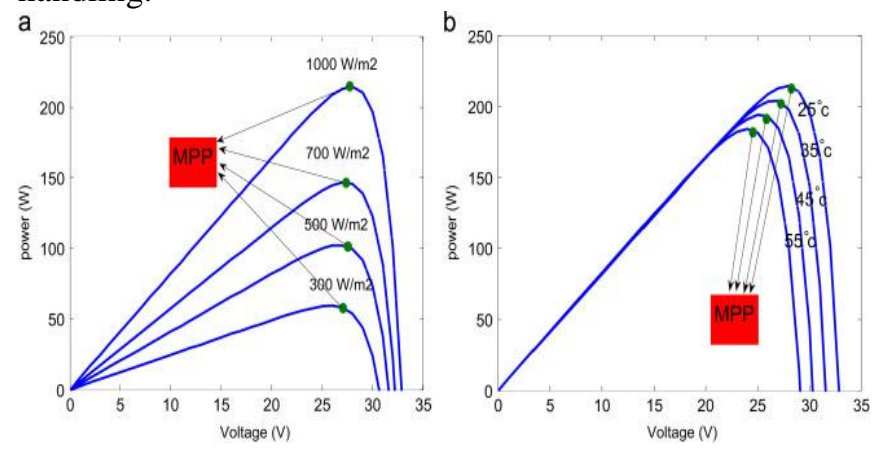

Fig. 1. Power reduction due to dust accumulation on solar panel

\section{B. Manual Cleaning Methodologies}

Various methods are techniques are utilized to perform automated cleaning in order to reduce human errors and to reduce manual labours in cleaning. Some of the strategies are listed below:

- Controller-based surface brushing

- Automatic water spray

- Cleaning robots

- Emerging methods

Automated cleaning provides error free and cleaning and reduces the work load of human beings. Micro controllers with sensored inputs are used to automate the cleaning system. Cleaning robots includes water supply equipment, cleaning device, adjustable bracket and walk across device. These automated cleaning robots are pre-programmed to get accustomed with the panel environment and act accordingly. This system provides high reliability, simple programming, increased output efficiency from the panels and stable working. Power, installation cost and the additional load are the major drawbacks faced here. Many emerging solutions are coming up in this category and the concept proposed here also comes under this.

\section{Other Cleaning Methods}

Some of the other latest cleaning techniques include electrostatic cleaning and nano dome cleaning technique. Fig.2. represents the electrostatic cleaning surface.

\section{Electrostatic Cleaning}

When there is too much energy on the surface of the solar panel, the board will attract non-charged and charged dust due to electromagnetic forces. The electrostatic forces between them will drive them off because they have the same electric charge. Finally, dust particles fly out of solar panels. This method though seems to be quite effective has a major disadvantage as it cannot work with wet dust. Thus, in tropical countries where there is more sunlight and rain, this strategy cannot be employed.Fig.3.represents the cleaning Rate of electrostatic panel cleaner. 


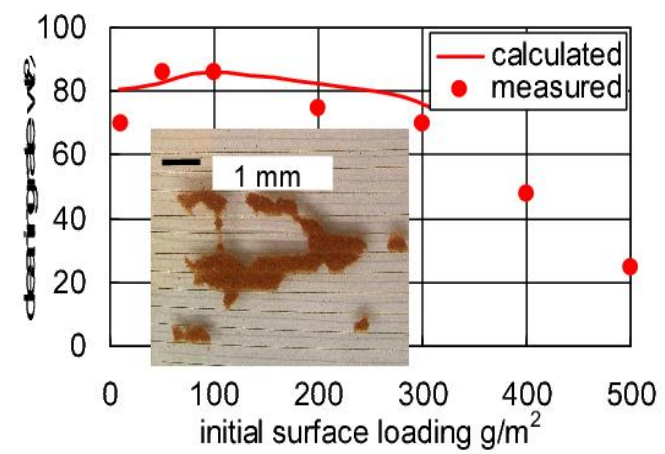

Relationshins hetween initial surface loading of sand

Fig. 2. Electrostatic cleaning surface [10]

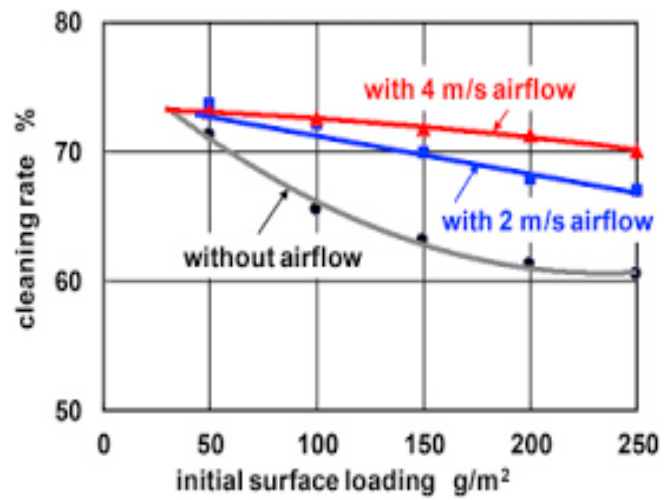

Fig. 3. Cleaning Rate of electrostatic panel cleaner

\section{E. Artificial Intelligence-Based Cleaning Robot}

This cleaning system which is designed is basically a panel cleaning system with algorithms programmed in order to make the self sufficient to think on its own and act accordingly. The system is very modular. The system can be said to be smart system in a way that cleaning process is carried out on the basis of dust analysis method and it is shown in fig.4. Dust analysis is used for determining which panel needs cleaning. For determining "Dusty Panel", an algorithm is developed which leads towards Cleaning of that specific panel. This has however faced drawbacks inters of cost, initial investment amount, complex for normal labours, requires highly skilled professionals and also the power required to run the cleaning system.

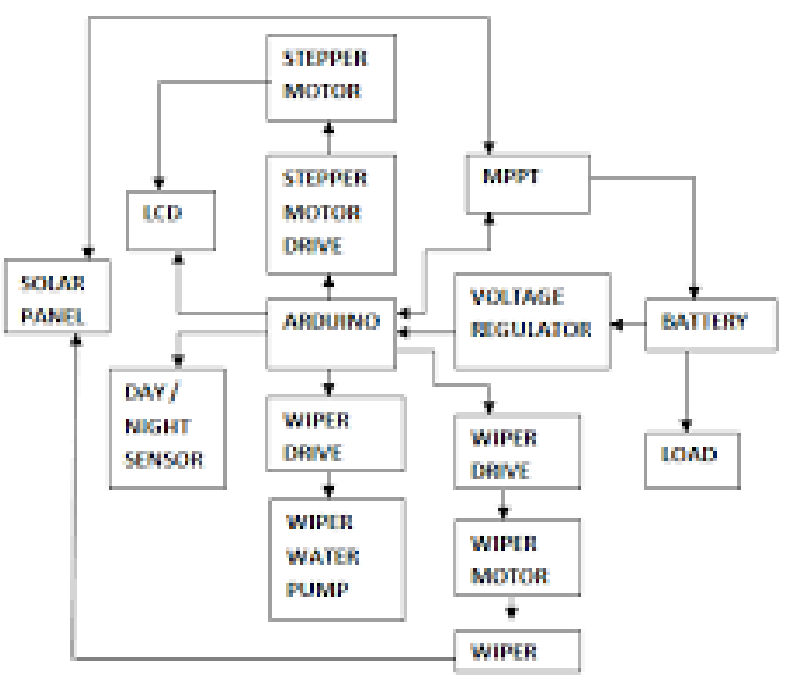

BI OCK DIAGRAM

Fig. 4. Block diagram of automated cleaning panel using water.[11]

\section{DESIGN AND IMPLEMENTATION OF PROPOSED SYSTEM}

The prototype consists of a supply panel and an Arduino controller with attached sensing elements, negative ion generator, vacuum suction module and motor driver. All the sensing elements and the driving elements are connected to the Arduino controller which provides necessary instruction according to the programmed format. Proposed block diagram is representing in fig.5. The cleaning module also consists of a self- sufficient power supply. The supply module is a small power source which is also supported by solar energy. The cleaner receives supply without any hindrance throughout the cleaning operation as the cleaning takes place only during day time. Further-more the controller is also programmed to clean periodically for effective cleaning. As soon as the sensing module it initiates the cleaning process and drives the motor throughout the panel length. The end of the panel is detected by an ultrasonic sensor which prevents disturbances in cleaner movement. The block diagram given below explains the design structure of the cleaner module and its connection sequence.

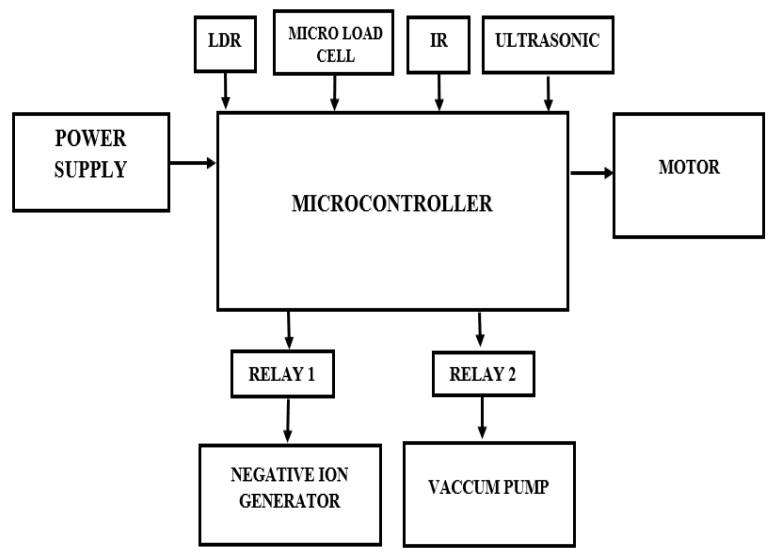

Fig. 5. Block Diagram

\section{RESULTS AND DISCUSSION}

\section{A. Computerized Cleaning System Operation}

The project uses a dry cleaning method using electrolytes and vacuum suction cleaning. The automatic cleaning system for PV panels is designed considering the following factors, dust detection or tracking technique, cleaning method and cleaning method. Therefore, the cleaning system is reciprocated by the amount of radiation produced from the sunlight and the software is programmed accordingly.

Since the disabled PV panel does not need to be cleaned at other times due to operation, the project is designed to monitor performance and perform cleaning work only during the day when the sun is on. The preloaded software was written using embedded $\mathrm{C}$ and uploaded to an Arduino microcontroller using the IDE provided by Arduino and simulated accordingly. 
The system consisted of two DC motors connected to the Arduino UNO through the control circuit of the L298 N motor driver. Monitoring circuit with driver shield and light sensor connected to Arduino UNO board. The light sensor is used to detect the presence of light and to check whether it is daylight or night. The microcontroller receives the signal from the light sensing element and responds by measuring the output power from the panel. If it is a clear day or the release is "high", the cleaning process will begin its process.

The cleaning algorithm stops its process when the output or output power is lower than the average value when the output from tea light sensor is low. According to the flow diagram below, if the light sensor detects light radiation and is not available, it is in idle or standby mode. When detecting solar radiation, the motor operates a cleaning system that generates forward-motion movement of the motor, and therefore the next sensor as in the flow diagram on the panel surface.

The cleaning hand moves until it reaches the limit switch, which then activates the reverse rotation of the motor. The reverse cycle moves the cleaning hand to its original position, where it is stopped by another range switch. The rotation process will continue until the measured output power does not exceed $20 \%$ of the average value. When there is too much energy on the surface of the solar panel, the board will attract non-charged and charged dust due to electromagnetic forces. Solar panel cleaner with electrostatic force generator will charge dust particles. The electrostatic forces between them will drive them off because they have the same electric charge. Dust particles eventually fly out of solar panels due to attracting forces. The negative ion generator removes the dust particles deposited on the solar panel when it reaches certain limit which is pre-programmed. Johnson Space Center (JSC-1A) dust deposition leads to considerable reduction in output voltage for each of the solar panels. The voltage drop reaches less than $20 \%$ of the initial voltage. As soon as the electro-dynamic shield is turned on, within two minutes the efficiency reaches beyond $90 \%$ and further increase gradually with respect to time.

\section{CONCLUSION}

The main intension behind this concept is to improve the panel efficiency without causing any damage to the panel irrespective of the cleaning done over it. Further it does not use water thereby helping in the existing water crisis. It is also clean and environmental friendly so that it reduces panel waste and there by contributing to the environment. With non contact type of cleaning it does not cause accidental damage to the panel.

Moreover it has two types of cleaning technology integrated together in a single system thereby ensuring high performance and efficiency of the cleaning system. By using vacuum suction tube it could easily clear the bird dropping which is a major problem faced while cleaning panels in countries like India. It also provides solution for the problem faced by the automated cleaning machines which are used nowadays. It also has a additional advantage of power supply

as it has its own self sufficient panel for running of the machine. The supply panel which is mounted on the cleaner module provides the necessary power required to run the motor of the cleaning system.

\section{REFERENCES}

1. KelebaoneTsamaase, Tapologo Ramasesane, IshmaelZibani, KagisoMotshidisi, "Automated dust detection and cleaning system of PV module", IOSR Journal of Electrical and Electronics Engineering vol. 12, no. 6, 2017, pp. 93-98.

2. V.B. Manimaran, "Design and Implementation of Solar-Wind Combo for Hybrid Energy Application," International Journal of MC Square Scientific Research, vol.5, no.1, 2013, pp. 37-42.

3. N. Vijayalakshmi, "Photovoltaic Fed Multilevel Inverter Design Using PODPWM Technique for Improved Power Quality," International Journal Of Advances In Signal And Image Sciences, vol. 5, no. 1, 2019, pp. 8-14.

4. R. Rajeswari, "Dynamic model and hybrid design of current fed switched inverter . for DMPPT fuel cell systems," International journal of advances in signal and image sciences, vol. 1, no. 1, 2015, pp. 29-40.

5. G. Praveenraj, "Energy Storage in Battery for Remote Area Using Wind DFIG Generation," International Journal Of Advances In Signal And Image Sciences, vol. 5, no. 1, 2019, pp. 22-28.

6. O. Sotehi, A. Chaker, and C. Maalouf, "Hybrid PV/T water solar collector for net zero energy building and fresh water production: A theoretical approach," Desalination, vol. 385, 2016, pp. 1-11.

7. M. S. Abd-Elhady, M. M. Fouad, and T. Khalil, "Improving the efficiency of photovoltaic (PV) panels by oil coating," Energy Conversion and Management, vol. 115, 2016, pp. 1-7.

8. V.S. Saravanan, S.K. Darvekar, "Solar Photovoltaic Panels Cleaning Methods A Review," International Journal of Pure and Applied Mathematics, vol.118,no. 24, 2018.

9. J.C. van der Linde, and C.J. Schabort, "The Effect of Different Types of Wash Water on Solar Panel Efficiency," International conference on advance of science, engineering, technology and natural resources (ICASETNR-16), 2016.

10. Kawamoto Hiroyuki, Guo Bing, "Improvement of an electrostatic cleaning system for removal of dust from solar panels," Journal of Electrostatics, vol. 91, 2018, pp 28-33.

11. C.I.Calle, et al, "Dust Particle Removal by Electrostatic and Di-electro-phoretic Forces with Applications to NASA Exploration Missions," Proc. ESA Annual Meeting on Electrostatics, vol.01, 2008, pp $1-14$.

12. Hiroyuki Kawamoto, Takuya Shibata, "Electrostatic cleaning system for removal of sand from solar panels," Photovoltaic Specialists Conference, 2013, DOI: $10.1109 /$ pvsc. 2013.6744107

13. M. R. Maghami, H. Hizam, C. Gomes, M.A. Radzi, M.I. Rezadad, and S Hajighorbani, "Power loss due to soiling on solar panel: A review," Renewable and Sustainable Energy Reviews, vol. 59, 2016, pp.1307-1316.

14. R. Divya, "Automatic cleaning of solar panel with maximum power tracking by using Arduino. Automatic cleaning of solar panel with maximum power tracking by using Arduino, "International Journal of Research Publication, vol. 2, no.1, 2018, pp.5-5.

\section{AUTHORS PROFILE}

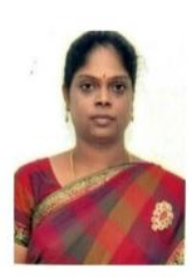

L. Chitra is an Associate Professor and Head in the department of EEE at Aarupadai Veedu Institute of Technology. She received her Bachelor Degree in Electronics and Instrumentation Engineering. She received her Master's Degree in Power Electronics and Drives in Anna University. She completed her PhD in Sathyabama Institute of Science and Technology in the field of Micro Electro Mechanical Systems for sensor design. Her research area includes MEMS, Renewable Energy, Process control, Sensors and Smart Sensors. She has published more than fifteen papers in International Conferences and Journals. She has a teaching experience of more than 18 years. She has received MNRE fund of Rs.1,50,000 for National Conference on Emerging Trends in New Renewable Energy Sources in the year 2014. She has also received a fund of Rs.1,00,000 from Unnat Bharat Abhiyan for Mobile Reverse osmosis based water purification system using Solar PV source for rural India in year 2019. 
She has also received a fund of Rs.50,000 from Unnat Bharat Abhiyan for DC Micro Grid based Solar PV generation to supply power to street lamp and common utilities in a village.

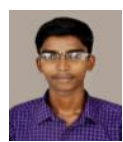

Ranjith R, born on 6 July 1999 in Chennai, currently he is a student, studying Mechatronics Final year at Aarupadai Veedu Institute of Technology, Chennai. He is one of the notable student in his college, for his interest in Research field. He has worked on many projects related to electrical, electronics and programming sector. One of his Defence Research and Development Organization project has been filed for patent. He is one of the key members of Cornerstone Automation company, which is a specialized company for research and development of Artificial Intelligence Robots and other Autonomous robots. His current research interests include power electronics, renewable energy, power transmission, etc., He is recognized for his outstanding performance on R\&D in SP Robotics Work company.

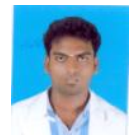

Praveen born in Chennai, He has completed his Bachelor's Degree at Aarupadai Veedu Institute of Technology, Vinayaka Mission's Research Foundation, Chennai. He is one of the notable student in his college, for his interest in the field. He has worked on many projects related to Renewable Energy, PLC, smart grid, etc., His current research interests include power electronics, renewable energy, power transmission, PLC, etc.,

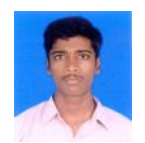

A Pragatheeswaran born in Chennai, He has completed his Bachelor's Degree at Aarupadai Veedu Institute of Technology, Vinayaka Mission's Research Foundation, Chennai. He has worked on many projects related to Renewable Energy, PLC, smart grid, etc.,. He is one of the notable student in his college, for his interest in the field of Automation and Renewable Energy. His current research interests include power electronics, renewable energy, power transmission, PLC, etc.,

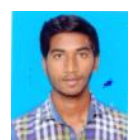

Divya raj was born in Chennai. He has completed his Bachelor's Degree at Aarupadai Veedu Institute of Technology, Vinayaka Mission's Research Foundation, Chennai. He is well known student in his college for his excellent Skills in his field of interest. He has worked on many projects related to Renewable Energy, PLC, smart grid, etc., His current research interests include power electronics, renewable energy, power transmission, PLC, etc., 